\title{
The case of hip dysplasia of an adult from the Roman Period site of Velebit (Serbia)
}

\author{
Ksenija Đukić ${ }^{*}$, Petar Milenković ${ }^{2}$, Tamara Pavlović ${ }^{1}$, Dragoslav Nestorović3 ${ }^{3}$ Raško Ramadanski ${ }^{4}$ \&
}

Marija Đurić ${ }^{1}$

\author{
${ }^{1}$ Laboratory of bone biology and bioanthropology, Institute of Anatomy, Faculty of Medicine, University of Belgrade, Dr Subotića 4/2, \\ Belgrade, Serbia \\ ${ }^{2}$ MediGroup, Diagnostic Centar Slavia, Knjeginje Zorke 25, Belgrade, Serbia \\ ${ }^{3}$ Center for Radiology and MRI Imaging, University Clinical Center of Serbia, Pasterova 2, Belgrade, Serbia \\ ${ }^{4}$ City Museum of Bečej, Glavna 25, Bečej, Serbia
}

*Corresponding author: ksenja.djukic@gmail.com

Received October $3^{\text {rd }}, 2021$

Accepted for publication November $26^{\text {th }}, 2021$

Online First November $30^{\text {th }}, 2021$

Keywords: hip dysplasia, perimortem cranial trauma, Roman Period, Serbia.

\section{Abstract}

Objective: This study is designed to reveal the diagnosis of a rare hip condition with an estimation of the possible cause of death.

Materials: Archaeological site of Velebit dated between the 3rd and 4th century AD is located in northern Serbia. Grave No 24 differs from others in the unusual position of the skeletal remains in situ.

Methods: The bioanthropological analyses included an estimation of skeletal preservation, cranial and postcranial skeletal measurements, estimation of sex and age at the moment of death, dental analysis and a paleopathological examination. This skeleton was analysed for signs of bone disease, using diagnostic paleopathological procedures comprising gross examination and CT scanning.

Results: The results revealed that the analysed male individual was 40 to 55 years of age. The bioanthropological analyses showed two deformities of the pelvic bones, each on the outer surface, located posteriorly and superiorly of the acetabular area. The observed lesions were characterised as type 4 of developmental dysplasia of the hip. In addition, a sharp lesion was observed in the right posterior region of squama of the occipital bone.

Conclusions: Our results clearly suggest that this individual had been suffering from hip dysplasia. The possible cause of death could be the observed head lesion. In addition, there is no skeletal conformation of unfavourable living conditions related to physiological stress and diet.

\section{Introduction}

Hip dysplasia is defined as a modelling failure of the acetabulum and, subsequently, the femoral head. People who suffer from hip dysplasia are born with the condition. In neonates, the condition is connected to a variety of anatomic abnormalities, from dysplastic to severe morphological findings that occur in rare idiopathic teratologic dislocations, usually in association with neurological diseases (Morrissy and Weinstein, 2006). Initially, this condition is commonly presented with delayed ossification of the lateral epiphysis of the acetabulum, which could lead to secondary dislocation during the first few months of life (Hefti et al., 2007). This occurs as the possible consequence of a subtle lack of coverage of the femoral head by the acetabulum i.e. a noncongruent femoral head and acetabulum (Manaster et al., 2016). The hip 
joint can become partially or completely dislocated. Subluxated hips are more susceptible to the onset of symptoms than completely dislocated hips (Morrissy and Weinstein, 2006). Usually, pain is not present during childhood, but most commonly presents as a symptom during adolescence and adulthood (Hefti et al., 2007; Manaster et al., 2016; https://hipdysplasia.org/developmental-dysplasia-ofthe-hip/infant-signs-and-symptomshipdysplasia.org ).

Geographical variation in the incidence of this disease has been noted, and both genetic and environmental elements are recognised as main background factors (Roberts and Manchester, 2007; Hefti et al., 2007; Mitchell and Redfern, 2007; Morrissy and Weinstein, 2006). In the contemporary population, this condition has an incidence of 1:1000, with a slight female predominance (1:5-8). Furthermore, a bilateral occurrence is recorded in $20 \%$ of cases (Manaster et al., 2016). In archaeological populations, hip dysplasia also tends to be more common in females than males, and occurs most frequently on the left side (Anderson, 2000). Analysing a series of 572 adults from the Medieval period in London, Mitchell and Redfern (2011) noted that the prevalence of developmental dysplasia of the hip (DDH) such as (acetabular dysplasia, subluxation, or dislocation) amounted to $1.7 \%$ of the investigated population (Mitchell and Redfern, 2011).

In bioanthropological literature, just a few systematic papers that included numerous cases of this pathological condition have been published thus far (Mitchell and Redfern, 2007; 2011). However, the importance of the case studies of this pathological condition should not be underestimated. Its importance lies not only in the rarity of the condition but also in the significant impact on a person's everyday life.

The aim of this case study is to present the hip dysplasia of an adult from the Roman Period site of Velebit (Serbia). We will discuss the differential diagnosis of the observed pathological conditions, outlining the development of hip dysplasia during this individual's life. Additionally, we will also evaluate the circumstances in which the perimortem cranial trauma found on the skull of the investigated individual occurred, as well as the potential outcomes.

\section{Materials and methods}

The archaeological site of Velebit is situated near the city of Senta (northern Serbia). According to unpublished archaeological records, the necropolis of Velebit is a multilayered site dated between the 2nd and 3 rd century AD. Among the excavated graves, grave no. 24 differs from the others in the unusual position of the skeletal remains in situ. The shallow grave pit was situated in humus soil and the well preserved skeleton in situ was in an extended supine position. However, the position of the lower extremities was unusual in that both legs were bent at the knees, with the right leg bent more than the left and resting over the left. The orientation of this individual was SW-NE, with a deviation of 15 degrees towards the north. There were no grave goods present.

The bioanthropological analyses included an estimation of skeletal preservation, cranial and post-cranial skeletal measurements, an estimation of sex and age at the moment of death, a reconstruction of body height, dental analysis and a paleopathological examination. The degree of preservation was evaluated according to a modified Mikić scheme, which takes into account the quantity of bones present as well as bone fragmentation (Mikić, 1978). Measurements were taken following standard osteological procedures (Buikstra and Ubelaker, 1994). The age assessment was based on the morphological appearance of the pubic symphysis, in accordance with the recommendations of Suchey-Brooks (Brooks and Suchey, 1990). The final estimation also included Iscan's methods (Iscan et al., $1984,1985)$, based on the appearance of the sternal end of the ribs, the cranial suture closures (Meindl and Lovejoy, 1985), dental wear (Gustafson, 1950) and the degenerative changes of the skeletons. Since hip bones present the most reliable indicators of sex in the human skeleton (Djuric et al., 2007), in this case study sex determination was primarily based on the dimorphic features of the os coxae (Buikstra and Ubelaker, 1994). An additional method for sex assessment was based on cranial morphology, and this was followed using standard bioanthropological criteria (Buikstra and 
Ubelaker, 1994). The reconstruction of body height was based on the length of the long bones (Trotter and Gleser, 1958). This skeleton was analysed for signs of bone disease, using diagnostic paleopathological procedures, comprising gross examination and CT scanning. The gross examination was based on a macroscopic observation of each bone including a detailed written and photographic description following the recommendation of Buikstra (2019), while CT scanning was conducted using a Siemens SOMATOM Sensation 16 with study reading in Carestream Vue PACS Power Viewer (ver. 12.0.0.5756).

\section{Results}

The skeletal remains of this individual were in a relatively good state of preservation (Fig 1).

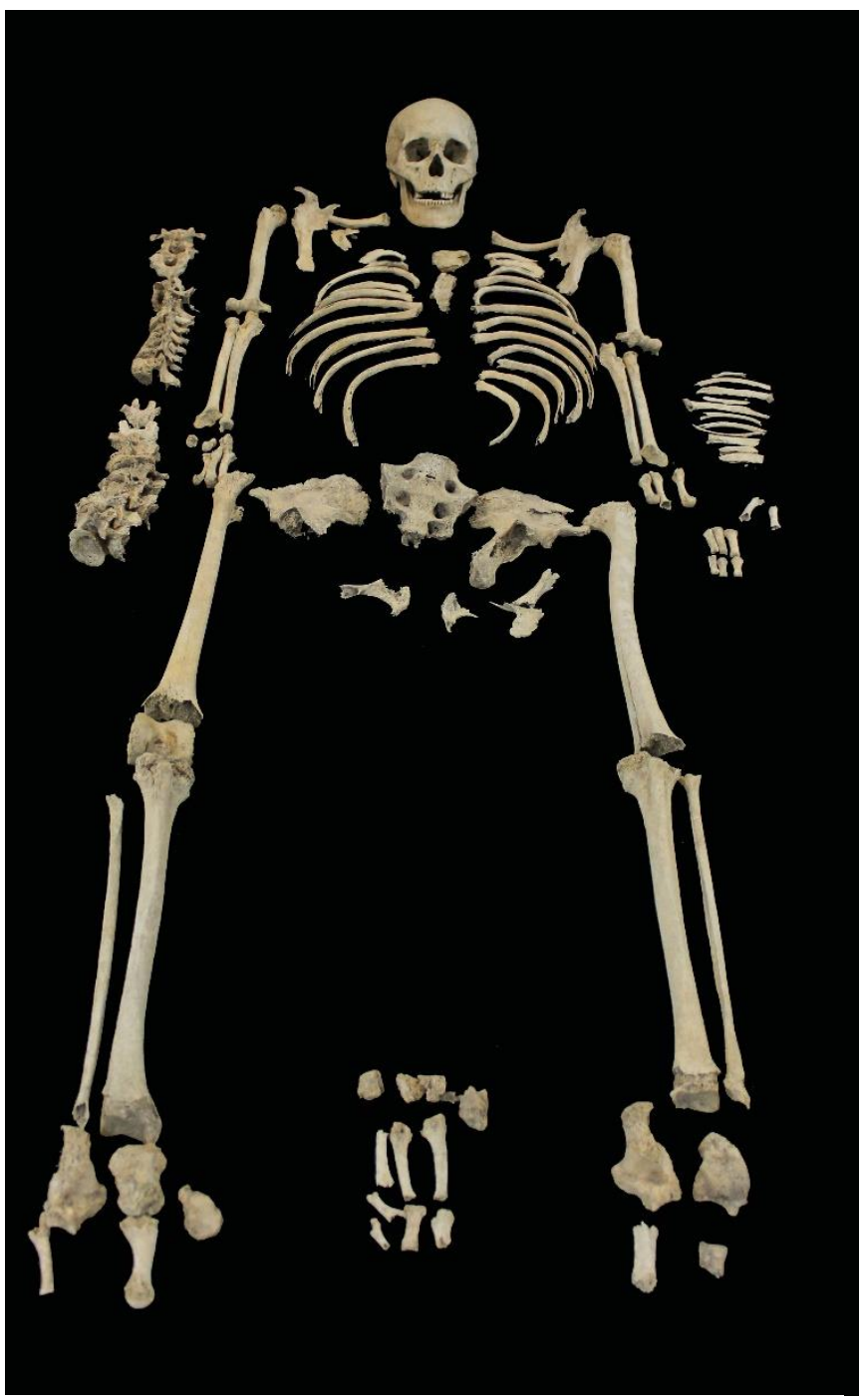

Figure 1: Skeletal remains from grave no. 24 (Photo and modification by Tamara Pavlović).
Based on the maximum length of the humerus and ulna, the body height has been reconstructed and estimated to be approximately $169 \mathrm{~cm}$. Bioanthropological analyses revealed that the male individual buried in this grave was 40 to 55 years of age at the moment of death. During the bioanthropological analyses, two deformities of the pelvic bones were noted, each on the outer surface, located posteriorly and superiorly of the acetabular area (Fig 2).

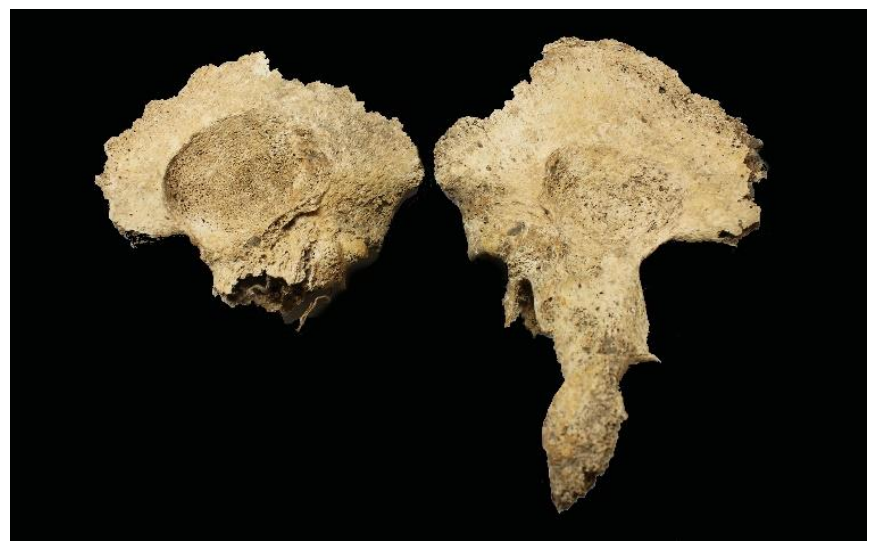

Figure 2: Deformities of pelvic bones (Photo and modification by Tamara Pavlović).

The surface bone was changed in comparison to the surrounding area, in the form of an oval bone impression, moderately deep with partially obtuse margins. A subtle new bone formation could be observed in the caudal half of the lesion periphery. The observed changes represented a false acetabulum. The condition was characterised as a type 4 developmental dysplasia of the hip, represented with a completely dislocated hip, and an inversion and highly possible hypotrophy of the labrum during life (Resnick and Kransdorf, 2005). On the left pelvic bone, in the expected area of true acetabulum, a triangular, narrow cavity with an uneven surface could be observed. This feature was partially preserved and represented an undeveloped true acetabulum. Unfortunately, on the right pelvic bone the expected area of the true acetabulum was not preserved.

A sharp lesion was observed in the right posterior region of the squama of the occipital bone (Figs 3 and 4). The find was described as a linear fracture with diastatic, dominantly sharp margins followed inferiorly by a tangential defect in the outer lamina, a possible repercussion of a loose fragment. Signs of discrete 


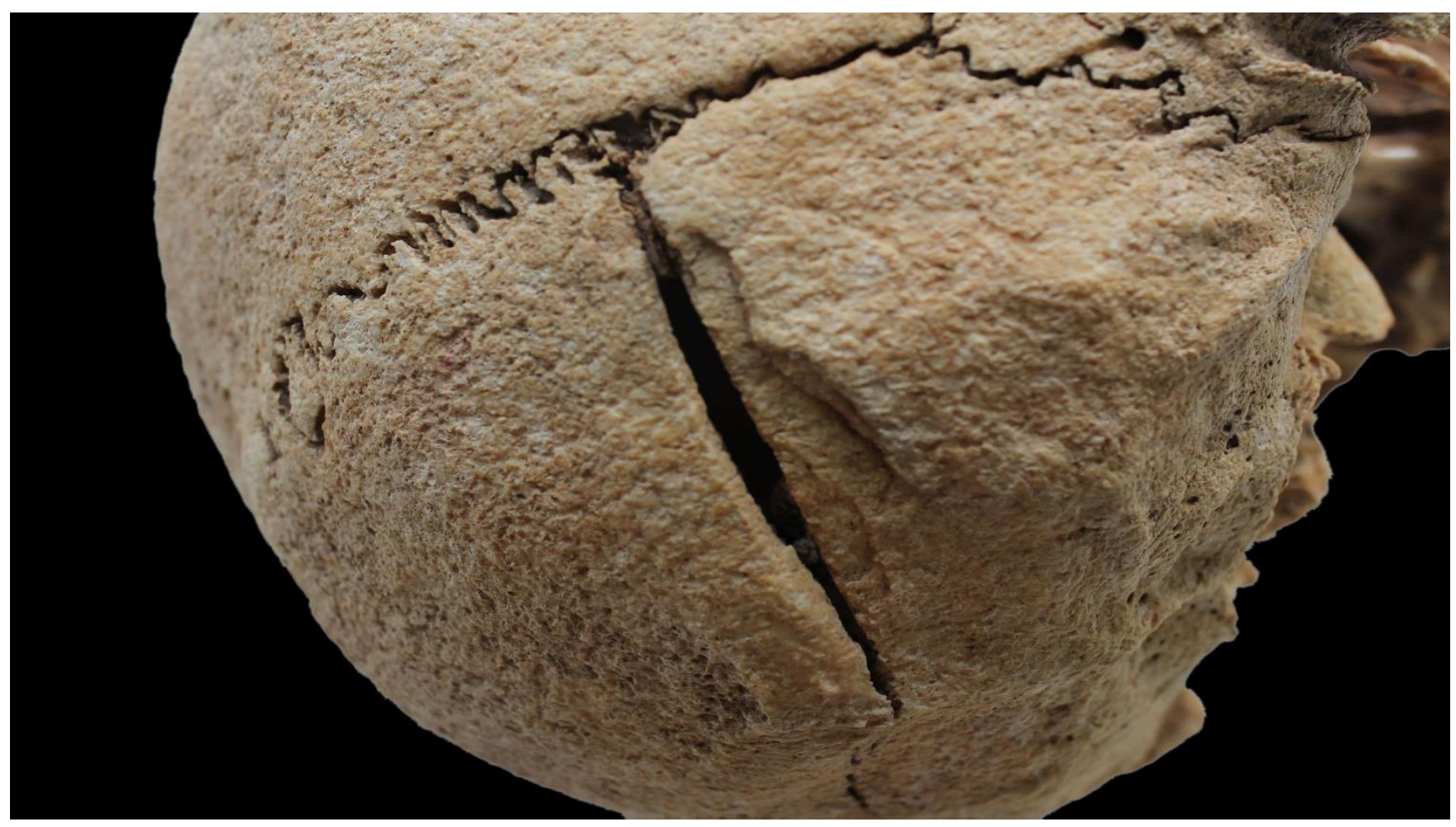

Figure 3: Occipital lesion (macroscopic oblique view) (Photo and modification by Tamara Pavlović).

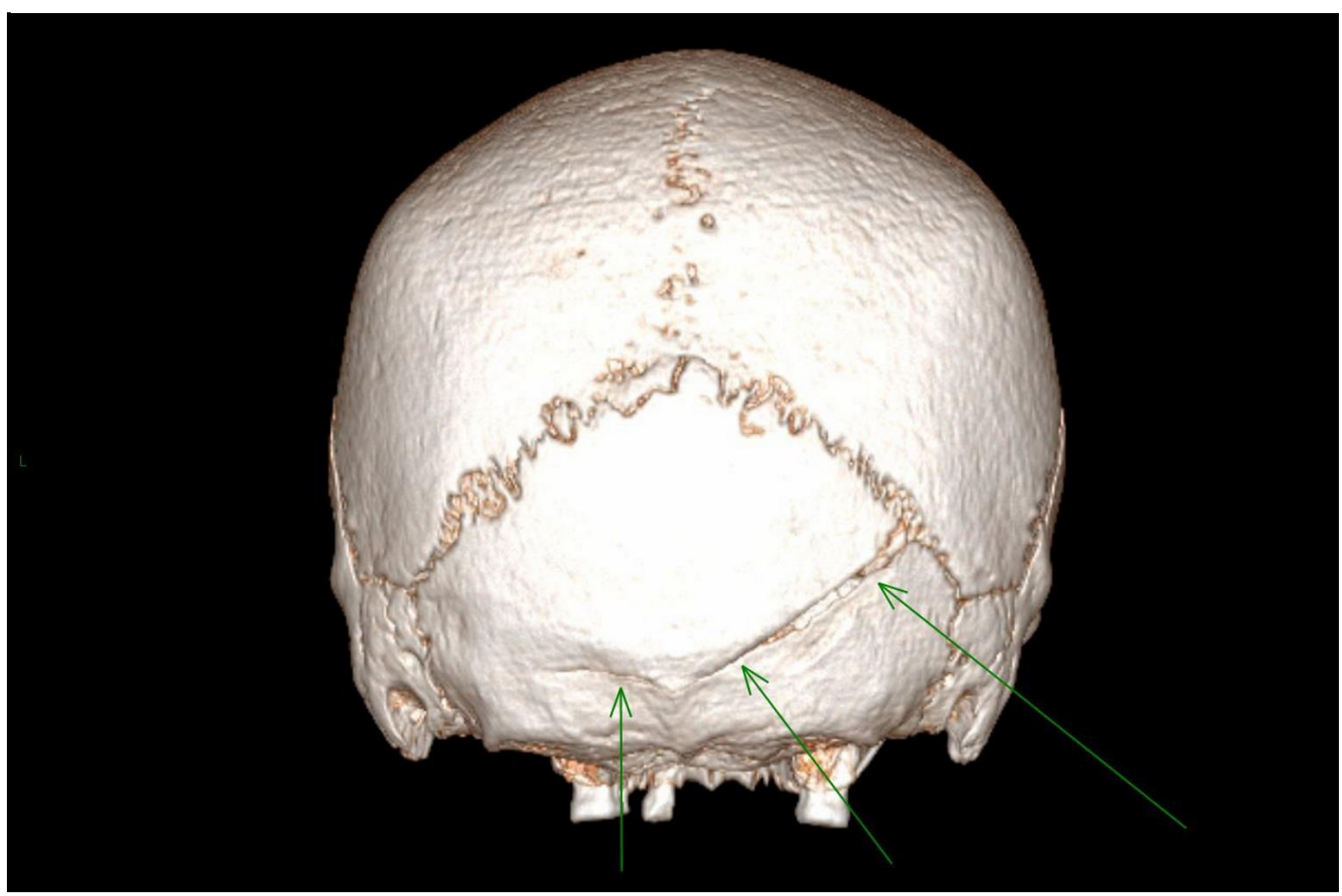

Figure 4: Occipital lesion (MDCT Volume Rendering, posterior view) (Photo and modification by Petar Milenković). 
callus formations were observed during radiological analyses, with the most pronounced records in the caudal third of the lesion, especially on the right side (Fig 5). At the same level on the left side, only the outer tabula were involved (Fig 6), while in the cranial and middle third, destruction affected both tabulas as well as the diploe.

In addition, malnutrition traces such as enamel hypoplasia, cribra orbitalia, subperiosteal inflammation, specific infectious diseases or metabolic diseases have not been noticed.

\section{Discussion and Conclusion}

\section{Discussion}

The normal development of the acetabulum occurs not only through growth of adjacent hip bones and the proximal femur, but is also highly influenced by vascularisation, muscle tone and forces transmitted through muscle attachments, as well as across the hip joint (Morrissy and Weinstein, 2006). The disturbance of physiological balance in these factors induce numerous health issues. Some of them are mild, such as asymmetry in the skin folds of the gluteal, thigh or labial region, while others are of more importance like limb length discrepancy, limited range of motion, waddling gait, and hyperlordosis of the lumbar spine (Morrissy and Weinstein, 2006). The most common disability is represented in a limitation of abduction as a consequence of adductor shortening due to hip subluxation or dislocation (Morrissy and Weinstein, 2006). Hip dysplasia can damage the cartilage lining the joint, leading to the early onset of osteoarthritis. This is the reason why, in cases with an early occurrence of osteoarthritis, attention should be focused on the possible underlying development of hip dysplasia (Manaster et al 2016). Although rare, a complication of untreated hip dislocation could be avascular necrosis of the femoral head, causing morphological alterations of the proximal femur that further leads to limb shortening, rotation and, finally, movement constriction. Even with complete dislocation, the

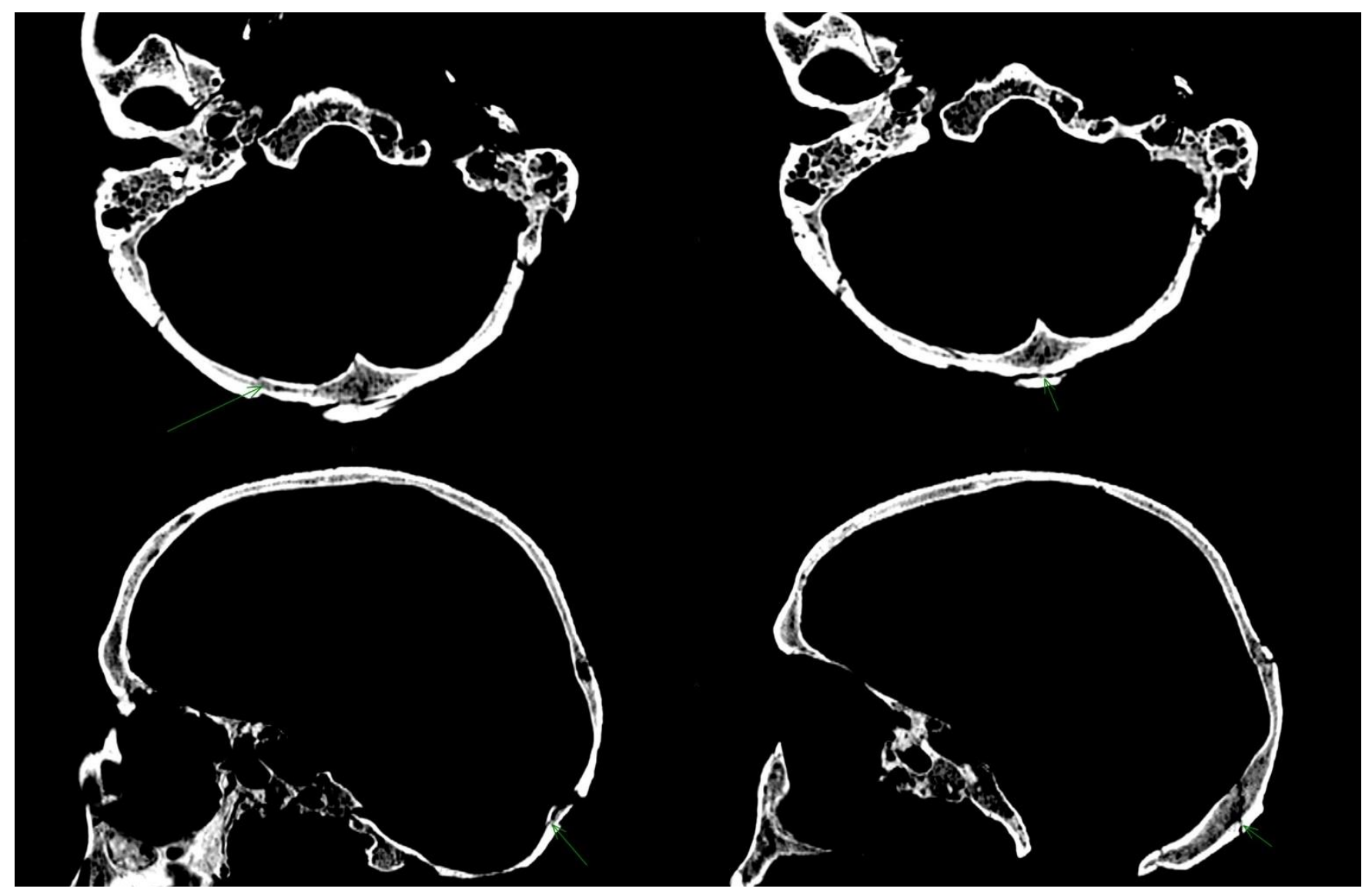

Figure 5: Calus formations (MDCT MPR Reconstructions) (Photo and modification by Petar Milenković). 


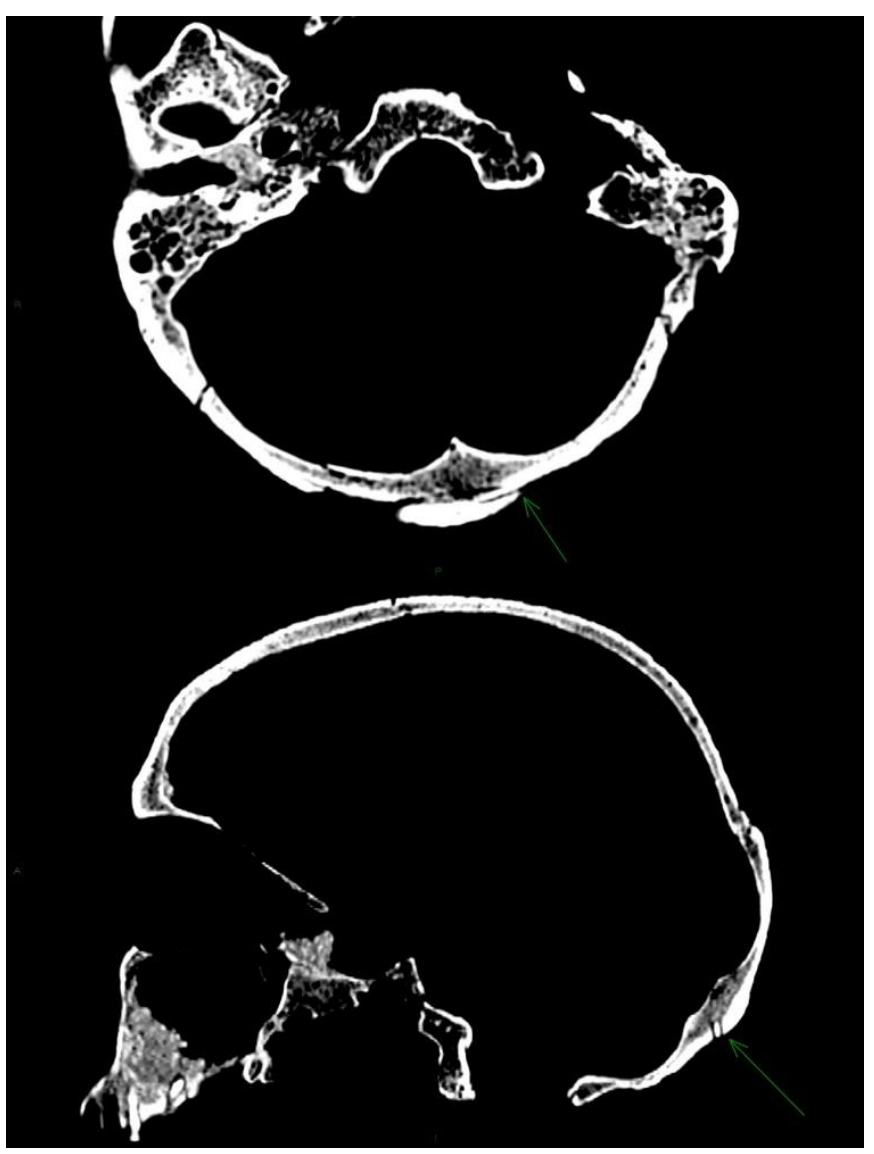

Figure 6: Predominant involvement of external tabula (MDCT MPR Reconstructions) (Photo and modification by Petar Milenković).

affected person may be with little or no functional disability. The level of disability is mainly affected by bilaterality and the state of development of the false acetabulum (Morrissy and Weinstein, 2006).

In hip dislocation there is a lack of physiological stimulus for acetabular development provided by the femoral head (Morrissy and Weinstein, 2006). The true acetabulum would be misshaped and filled with fibrofatty material (Resnick and Kransdorf, 2005). This results in the most severe form of the disease characterised by an absence of a formed acetabulum, with the femoral head articulating with the iliac bone, creating a pseudoacetubulum i.e. a false acetabulum (Manaster et al 2016). The absence of a false acetabulum allows a good range of motion and little functional disability, while a well-developed false actetabulum leads to degenerative joint diseases (Morrissy and Weinstein, 2006).
In the present case, the anatomical features of the true acetabulum indicated an early abruption of physiological development, which resulted in an irregular shape, size and surface. Based on the aforementioned, the presence of a false acetabulum undoubtedly leads to a diagnosis of hip dysplasia. Due to the morphological characteristics, the affected person probably suffered from the so-called swaying gait.

Abnormal gait, incapacitating pain, and the occurrence of severe arthritis certainly would be limiting factors in the performance of any daily activity that includes the action of the lower limbs. Therefore, an active role in activities such as hunting, agriculture or even warfare, which in many ancient societies represented the basis of economic development, must have been restricted or even not possible (Roberts and Manchester, 2007). Moreover, the health situation in which these people found themselves also demanded some form of care that had to be constant and daily. In the presented case, based on the results of bioantrhoplogical analysis, traces of some malnutrition conditions, such as enamel hypoplasia, cribra orbitalia, subperiosteal inflammation, specific infectious diseases or metabolic diseases, were not noticed. Although very generally, this could suggest that this person had a satisfactory diet and living conditions throughout their life, despite the potential limitations that may have arisen as a result of the presented hip disease.

Taking into account that in ancient societies this condition became visible in the period when a child started walking, it seems that the application of any treatment would be too late and with poor results (Roberts and Manchester, 2007). The fact that the developmental hip dysplasia would not resolve spontaneously in the absence of treatment (Mitchell and Redfern, 2007) further outlines the importance of early detection, even today. Even from the standpoint of modern medicine, it is not possible to predict the outcome of developmental hip dysplasia in neonates, therefore, all cases with clinically detectable hip instability should be treated (Morrissy and Weinstein, 2006). According to contemporary medical practice, secondary adaptive changes in the hip joint take place even after six months of life, making simple treatment 
options ineffective and leaving techniques of closed and open reduction as the only possible options (Morrissy and Weinstein, 2006). Until the age of three, closed reduction is recommended, while open reduction is applied only in unsuccessful cases. Later in the course of life, i.e. after the age of five, operative treatment is only recommended in unilateral dislocations, while bilateral dislocations are treated with open reduction only if a false acetabulum has already been formed (Hefti et al., 2007). The possibility of normal acetabular development is less likely with an increased age of detection (Morrissy and Weinstein, 2006). It is obvious that modern diagnostic techniques were not possible in that time and that any applied treatment would have been too late, leaving the possibility of visible marks on dry bones. To our knowledge, there is no evidence of any effective treatment of this condition during the Roman Period, although some simple techniques would have been possible. Thus, any traces of pathological conditions in the region of the spine, hips, or feet should be precisely recorded and carefully investigated. If there is the possibility, analyses of factors such as cultural practices, attitude towards health or available obstetric care should not be neglected.

The previously described blow to the head would cause laceration of the occipital brain tissue, due to the direct effect of the blade and bone fragment displacement intracranially. Usually, this is followed by the development of hemorrhagic contusion sites, traumatic subarachnoid hemorrhage, the formation of a subdural or epidural hematoma with a compression effect, and pneumocephalus. The formation of "bridging" bone tissue between fragments suggests that this individual did not subdue to the primary effects of head trauma, but later, due to secondary effects, most possibly an infection of the soft tissue (meningitis, encephalitis) (Osborne 2018). The partial obtuse margins of the skull lesion showed diminished signs of healing, suggesting perimortal trauma delivered by a long, sharp weapon. The observed head lesion should be considered as a possible cause of death.

\section{Conclusion}

The results of our analyses clearly suggest that this individual had been living with a health problem for decades, suffering from hip dysplasia during life. The condition was progressive and led to an abnormal development of the hips, with the presence of a false acetabulum. The position in the grave suggested the presence of lower limb contractures, which could develop in untreated cases of developmental hip dysplasia. The observed features could have evolved throughout life, incapacitating normal function, making even simple everyday activities challenging and painful. This led us to the conclusion that any previously applied treatment in this case would have been unsuccessful. Unfortunately, the poor preservation of the proximal end of both femurs as well as vertebrae limited more detailed analyses of this condition. The possible cause of death could be the observed head lesion. However, signs of healing signal that this person did not succumb to the injury on the spot, but most likely sometime after, probably due to an infection of the brain tissue.

In addition, there is no confirmation of unfavourable living conditions related to diet. It is important, however, to note that, in this particular grave, archaeologists found no grave goods, so the social status of this individual cannot be discussed.

A detailed examination and reconstruction of health problems that were incurable and that prevented an individual performing day-to-day activities would allow us to better understand the overall attitude of the community towards disabled persons and health in general.

\section{Acknowledgements}

This work was supported by the Ministry of Education, Science and Technological Development of Serbia; Grant number: III 45005.

\section{References}

Anderson, T. (2000). 'Congenital conditions and neoplastic disease in palaeopathology' In M. Cox, S. Mays (Eds.), Human Osteology in Archaeology and Forensic Science (pp. 199-225). Cambridge: Cambridge University Press.

Brooks, S. Suchey, J. M. (1990). Skeletal age determination based on the os pubis: A comparison of the Acsádi-Nemeskéri and SucheyBrooks methods. Human Evolution 5(3), 227-38. https://doi.org/10.1007/BF02437238 
Buikstra, J.U., \& Ubelaker, D. (1994). Standards for Data Collection from Human Skeletal Remains. Arkansas: Archaeological Survey Press.

Djuric, M. Dunjic, D. Djonic, D. Skinner, M. (2007). Identification of victims from two mass graves in Serbia: a critical evaluation of classical markers of identity. Forensic Science International 172(23), 125-129. doi:10.1016/j.forsciint.2007.01.003

Gustafson, G. (1950). Age determination on teeth. Journal of the American Dental Association 41(1), 45-54. doi:10.14219/jada.archive.1950.0132

Hefti, F. Brunner, R. Hasler, C.C. Jundt, G. (2007). Pediatric Orthopedics in Practice. Berlin-Heidelberg: Springer.

International Hip Dysplasia Institute SAD (2018). Hip DysplasiaInfant and Child. https://hipdysplasia.org/developmental-dysplasiaof-the-hip/infant-signs-and-symptoms/ (accessed 13 Jun 2019).

Işcan, M.Y. Loth, S.R. Wright, R.K. (1984). Metamorphosis at the sternal rib end: A new method to estimate age at death in white males. American Journal of Physical Anthropology 65(2), 147-56. doi:10.1002/ajpa.1330650206

Iscan, M.Y. Loth, S.R. Wright, R.K. (1985). Age estimation from the rib by phase analysis: white females. Journal of Forensic Science 30(3), 853-63. doi:10.1520/jfs11776j

Manaster, B.J. (2016). Diagnostic Imaging. Muskuloskeletal: nontraumatic disease. Philadelphia: Elsevier.

Meindl, R.S. Lovejoy. C.O. (1985). Ectocranial suture closure: a revised method for the determination of skeletal age at death based on the lateral-anterior sutures. American Journal of Physical Anthropology 68(1), 57-66. doi: 10.1002/ajpa.1330680106

Mikić, Ž. (1978). O antropološkoj metodologiji terenske obrade skeletnih ostataka. Godičnjak Centra za balkanološka ispitivanja ANUBiH 16/14, 201-242.

Mitchell, P.D. Redfern, C.R. (2007). The Prevalence of Dislocation in Developmental Dysplasia of the Hip in Britain Over the Past Thousand Years. Journal of Pediatric Orthopaedics 27 (8), 890-892. doi:10.1097/bpo.0b013e31815a6091

Mitchell, P.D. Redfern, C.R. (2011). Brief communication: Developmental dysplasia of the hip in medieval London. American Journal of Physical Anthropology 144 (3), 478-484. doi:10.1002/ajpa.21448

Morrissy, R.T. Weinstein, S.L. (2006). Lovell \& Winter's Pediatric Orthopaedics. Philadelphia: Lippincott Williams \& Wilkins.

Osborn, G. A. (2018). Anne G. Osborn's Brain: Imaging, Pathology, and Anatomy. Elsevier.

Resnick, D. Kransdorf, M.J. (2005). Bone and joint imaging. Philadelphia: Elsevier.

Roberts, C. \& Manchester, K. (2007). The Archaeology of Disease. Ithaca: Cornell University Press.

Trotter, M. \& Gleser, G. (1958). A re-evaluation of estimation of stature based on measurements taken during life and the long bones after death. American Journal of Physical Anthropology 16, 79-123. dot: 10.1002/ajpa.1330160106 